\title{
Os blogs como meios de comunicação política
}

\section{Joaquim Paulo Serra}

Doutor em Ciências da Comunicação e professor catedrático no Departamento de Comunicação e Artes da Universidade da Beira Interior (UBI), onde também é investigador no Labcom.IFP. É autor dos livros A informação como utopia (1998), Informação e sentido: o estatuto epistemológico da informação (2003) e Manual de teoria da comunicação (2008), coautor do livro Informação e persuasão na web (2009) e coorganizador de várias outras obras.

E-mail: pserra@ubi.pt
Resumo: O texto analisa e discute o papel dos blogs portugueses enquanto meios de comunicação política. Nas nossas sociedades mediatizadas, a atividade política é indissociável das mídias, que constituem uma espécie de "parlamento mediático" onde tudo se decide antes da decisão propriamente política. É precisamente nesse "parlamento" que os blogs procuram influir e, consequentemente, no parlamento propriamente dito e na ação governativa; ou seja, a principal influência dos blogs enquadra-se naquilo a que se tem chamado agendamento intermediático. $E$, na medida em que os blogs dão voz a muitos cidadãos alheios às mídias mainstream, podem ser vistos como representação de um alargamento da esfera pública mesmo se, em alguns casos, são utilizados como mais um meio ao serviço da "politics as usual".

Palavras-chave: Blogs; Comunicação política; Agendamento; Esfera pública.

\section{Title: Blogs as means of political communication}

Abstract: The paper analyzes and discusses the role of portuguese blogs as a means of political communication. In our mediatized societies, political activity is inseparable from media, which constitute a kind of "media parliament" where everything is decided before the specifically political decision. It is precisely this "parliament" that blogs seek to influence and thereby the parliament itself and governmental action; that is, the main influence of blogs fits in what has been called intermedia agenda-setting. And to the extent that blogs give voice to many citizens and voices outside the mainstream media, they can be seen as representing an extension of the public sphere - even if in some cases they are used as one more tool of the "politics as usual".

Keywords: Blogs; Political communication; Agenda-setting; Public sphere. 


\section{Introdução}

${ }^{1}$ Tradução livre do original de:

"Freedom of press is guaranteed only to those who own one".
A conhecida afirmação de Abbott Joseph Liebling (1960) de que "A liberdade de imprensa é garantida apenas àqueles que possuem uma" ${ }^{1}$ foi utilizada, por vezes, para justificar um suposto "jornalismo do cidadão" (GILLMOR, 2004). Hoje, aparentemente ultrapassada essa discussão, é inegável que a Web 2.0 e, em particular, os blogs trouxeram aos cidadãos possibilidades de publicação que puseram em causa o tradicional monopólio das mídias noticiosas e dos jornalistas profissionais para produzir e distribuir informação relevante e credível-sobretudo na área da política.

Pôr em causa não significa, obviamente, substituir. De fato, a afirmação dos blogs foi se fazendo, gradualmente, não por uma substituição das mídias noticiosas tradicionais, mas pela sua afirmação como meios tendentes à complementação, aprofundamento e, muitas vezes, retificação da informação dessas mesmas mídias - e, assim, de enriquecimento da informação publicamente disponível.

Apesar de alguma polêmica sobre a questão, considera-se geralmente que o primeiro blog português teria sido o Macacos sem Galho, cuja criação remonta a 30 de março de 1999 - portanto, cerca de dois anos depois de John Barge ter cunhado o termo weblog, "diário da rede".

Contudo, a grande explosão da blogosfera em Portugal viria a dar-se apenas em 2003, tendo contribuído decisivamente para isso fatores como a atenção que as mídias tradicionais começaram a dedicar ao fenômeno, ou a adesão de personagens mediáticas como Pacheco Pereira, que criou o blog Abrupto (CANAVILHAS, 2005, p. 86-87). Esta é uma época dominada pelos blogs políticos, claramente marcada pela oposição esquerda-direita, simbolizada em blogs como - Coluna Infame - de direita, iniciado em 15 de outubro de 2002 por João Pereira Coutinho, Pedro Lomba e Pedro Mexia -, e o Blog de Esquerda - de esquerda, iniciado em 01 de janeiro de 2003 por José Mário Silva e Manuel Deniz Silva (CANAVILHAS, 2005, p. 87-88).

A partir de 2003, gradualmente verifica-se não apenas a afirmação, mas mesmo certa institucionalização dos blogs, que se traduz no aumento de sua influência na esfera mediática.

Exemplos significativos são a inclusão de blogs, criados de raiz ou já existentes, nos sites de jornais nacionais de referência, como o semanário Expresso ou o diário Público. Ou a contratação de ex-bloggers, incluindo colunistas das mídias mainstream como, por exemplo, Ricardo Araújo Pereira (Visão), Henrique Raposo e Daniel Oliveira (Expresso), João Pereira Coutinho (Correio da Manhã) e Rui Tavares (Público) (PENA; LUÍS, 2009). Ou, ainda, o fato de no dia 14 de setembro de 2009, e por iniciativa dos jornalistas Filipe Caetano e Nuno Ramos de Almeida, a TVI24 online (tvi24.pt) ter dado início ao programa Combate de Blogs, pondo frente a frente bloggers de direita e de esquerda debatendo as legislativas de 2009. Posteriormente, em abril de 2010, o programa passou para a TVI24. Com frequência semanal e uma duração de cerca de 30 minutos, o programa foi emitido primeiro ao domingo, depois à terça-feira e, finalmente, ao sábado à noite, tendo tido a sua última emissão em 04 de agosto de 2012 (O FIM, 2012; SILVA, 2012, p. 2-3).

E mesmo se também a comunicação, assim como os meios que a permitem, obedecem às injunções da moda - e, principalmente, à dupla injunção da imitação e da igualização social, por um lado, e da diferenciação individual e da mudança, por outro (SIMMEL, 1904) -, os blogs, apesar de desafiados em algumas das suas funções por "modas" como o Twitter ou o Facebook, têm mantido a sua importância.

Como o mostra a própria história dos blogs, uma das áreas em que essa importância tem sido mais visível é a área da política, entendida aqui não no 
seu sentido estrito, de atividade político-partidária ou governativa, mas no sentido global, de atividade centrada nas questões da polis, da coisa pública. É precisamente o papel dos blogs no contexto daquilo que a seguir chamamos "parlamento mediático", ou sistema político-mediático, que este nosso texto se propõe a analisar.

O texto é constituído por quatro seções principais. Na primeira, intitulada "A política e o parlamento mediático", procuramos caracterizar a natureza da política nas sociedades mediatizadas, que são as nossas a partir da metáfora do "parlamento mediático" - um parlamento cuja existência se dá na mídia e pela mídia, a cujas regras e filtros os agentes políticos devem submeter-se. Na segunda seção, que leva o título "A questão da influência dos blogs políticos", discutimos o grau e a forma de influência dos blogs políticos sobre o "parlamento mediático", tal como caraterizado na seção anterior. Na terceira seção, "Os blogs e as mídias mainstream", discutimos a relação entre os blogs e as mídias jornalísticas convencionais a partir de duas questões conexas: o agendamento noticioso e a utilização de mecanismos de gatekeeping. Na quarta e última seção, com o título "Os velhos problemas da esfera pública", analisamos a blogosfera a partir do conceito habermasiano de "esfera pública", incluindo a questão da sua eventual "refeudalização". O texto termina com as "Considerações finais", que cristalizam um conjunto de conclusões que decorrem das quatro seções referidas.

Ainda que centrado no caso português e tendo em conta o carácter global que os fenômenos político-mediáticos hoje assumem, cremos que muitas dessas conclusões são facilmente transponíveis para outros países e latitudes.

\section{A política e o "parlamento mediático"}

Se é verdade que a relação entre a política e as mídias existe como problema praticamente desde que elas existem, não é menos verdade que a natureza desse problema tem mudado ao longo dos tempos.

Tradicionalmente, os políticos encaram as mídias como meros meios de transmissão das suas mensagens para os cidadãos/eleitores, e os jornalistas como mensageiros dessas mensagens - tornando-se a relação entre ambas as partes problemáticas apenas quando as mensagens não chegam, ou não chegam da forma pretendida aos cidadãos/eleitores.

Hoje, as mídias não se reduzem a meros meios nem os jornalistas a mensageiros - uns e outros transformaram-se em agentes políticos de primeiro plano. Não no sentido em que efetuam a defesa de uma ideologia ou de uma corrente política (o que excepcionalmente também podem fazer), mas no sentido em que as mídias e, em particular, a televisão, se tornaram o verdadeiro parlamento do nosso tempo como o comprova, também, o fato de cada parlamento querer a sua televisão (no caso português, a ARTV). Com efeito, é nas mídias, e não já no Parlamento, que as discussões políticas não só se iniciam, mas também se tornam decisivas - no duplo sentido de ganharem importância e de levarem a uma decisão. Em regra, ao tradicional Parlamento cabe, num momento posterior, ratificar as decisões já tomadas no "parlamento mediático".

Não tem, assim, sentido - e, mais tarde ou mais cedo, revela-se como completamente contraproducente - que qualquer governo considere as mídias como a oposição, especialmente quando a oposição propriamente dita tem uma expressão reduzida. Com efeito, as mídias tendem a tratar todos os políticos, sejam eles do governo ou da oposição, de forma idêntica. E que forma é essa? Dado o valor supremo da objetividade que guia o modo como procuram dar as suas notícias - e que os impede de tomar posições ideológicas e políticas a favor ou contra os políticos e as políticas -, as mídias tendem a centrar-se nos fatos, isto é, nos protagonistas da política e nas suas ações, procurando evidenciar a 
distância entre o que se diz e o que se faz; o que se aparenta ser e o que se é, em suma, as questões éticas, de carácter ou credibilidade. Essa posição das mídias ganha ainda mais força quando hoje as ideologias e as políticas tendem a ser avaliadas pelos seus efeitos mais ou menos pragmáticos e imediatos - e isso tanto pelos que diagnosticam o fim da ideologia como por aqueles que, pelo contrário, prognosticam o regresso da mesma.

É fácil concluir que o "parlamento mediático" de que aqui falamos tem mais a ver com a descrição luhmanniana do que com a descrição habermasiana de "mídia" e da "opinião pública" (LUHMANN,1993; HABERMAS, 1989). De fato, longe de permitir que cada cidadão entre na discussão política de forma racional e igualitária, de forma a conseguir um resultado comum (a tal "opinião pública"), o que se passa é que os cidadãos assistem à distância (tele-assistem) à discussão que se vai fazendo entre os diversos intervenientes políticos e ao comentário que os jornalistas vão fazendo das posições desses intervenientes.

Ao contrário do Parlamento, que os políticos que lideram no poder ou na oposição podem controlar de forma mais ou menos completa e eficaz, o "parlamento mediático" não tem esse controle. A razão está em ser um espaço que obedece às suas próprias regras e filtros, e em que coincidem diversos poderes e micropoderes que se aliam, se cruzam e combatem entre si: dos donos e/ou acionistas, dos diretores e editores, dos jornalistas com a sua deontologia e as suas rotinas próprias, dos partidos políticos e dos políticos individualmente considerados, dos movimentos de cidadãos etc.

Assim, o "parlamento mediático" é constituído pelo conjunto de órgãos de comunicação social que exercem a mediação entre os políticos e os cidadãos, mas em que não governam nem os primeiros nem os segundos. Sendo verdade que também o Parlamento exerce essa função de mediação, exerce-a apenas de forma periódica e limitada no tempo, principalmente quanto aos atos eleitorais apropriados; já o "parlamento mediático" exerce essa mediação todos os dias e, com os novos meios eletrônicos, cada vez mais a todas as horas e mesmo a todos os minutos.

Ao emergirem, os blogs, sobretude os mais centrados na atualidade política, reivindicam essencialmente uma função de intervenção (de observação e crítica) neste "parlamento mediático", feita em nome do interesse público, mesmo que

${ }^{2}$ Aquilo que dizemos neste texto sobre os blogs aplica-se também, em maior ou menor grau, a redes sociais como o Twitter ou o Facebook.

\footnotetext{
${ }^{3}$ Tradução livre do original: "There is good reason to believe that blogs are changing politics, but we don't know exactly how."
}

seja difícil, senão impossível, delimitar tal conceito. ${ }^{2}$ É aos blogs que se atribue tal função que se costuma chamar de "blogs políticos". Por conseguinte, neste contexto, "políticos" são não propriamente os blogs mantidos por partidos ou membros dos partidos no desempenho de certas funções partidárias ou estatais (deputados, por exemplo), até porque, como o demonstram vários estudos (SERRA, 2012), tais blogs acabam por ter pouco significado qualitativo e qualitativo na blogosfera nacional. São, antes, os blogs dos cidadãos que se pronunciam sobre questões públicas de interesse geral e que, para além disso, "são mantidos por cidadãos comuns ou, pelo menos, por cidadãos que, mesmo sendo eleitos ou no exercício de funções institucionais, não mantêm esse espaço em representação de posições partidárias ou lugares políticos" (MORAIS, 2013, p.13).

Mas qual é, mais concretamente, a influência dos blogs políticos? E como é exercida? Essa é a questão que trataremos a seguir.

\section{A questão da influência dos blogs políticos}

Não restam dúvidas de que a afirmação de Drezner e Farrell (2008a, p. 1) de que "Há boas razões para acreditar que os blogs estão a mudar a politica, mas não sabemos exatamente como" ${ }^{3}$ continua a ser, em grande parte, verdadeira.

Comecemos pela quantidade. Os blogs sobre política representavam, em 2006, apenas $4.3 \%$ da blogosfera portuguesa - uma percentagem desproporcionada 
em relação à grande visibilidade e publicidade que lhe são conferidas nas mídias tradicionais (CARDOSO; ESPANHA; CHETA, 2008).

Também em termos de leitura os blogs sobre atualidade política estão longe de ser os mais lidos. Assim, dos 1797 blogs que integravam o Blogómetro em 20 de julho de 2013 (BLOGÓMETRO, 2013), a lista média diária de visitas era a seguinte:

Tabela 1 - Lista por média diária de visitas (20 de julho de 2013)

\begin{tabular}{|c|c|c|}
\hline Pos. & Nome & Média Visitas \\
\hline 1 & Visão de Mercado & 49445 \\
\hline 2 & A pipoca mais doce & 33184 \\
\hline 3 & Blog DeAr Lindo & 25479 \\
\hline 4 & Cocó na Fralda & 14122 \\
\hline 5 & mini-saia & 14085 \\
\hline 6 & Wrestling.PT & 12940 \\
\hline 7 & O Arrumadinho & 9863 \\
\hline 8 & Professores Lusos & 9810 \\
\hline 9 & As Minhas Receitas & 9576 \\
\hline 10 & Vídeos divertidos & 9017 \\
\hline 11 & O Cacifo do Paulinho & 8681 \\
\hline 12 & A Educação do meu Umbigo & 8524 \\
\hline 13 & Portuguese Celebrity Girls & 7979 \\
\hline 14 & E Deus Criou a Mulher & 7876 \\
\hline 15 & Super Sporting & 6342 \\
\hline 16 & Nomes e mais nomes & 6327 \\
\hline 17 & Astropt & 5643 \\
\hline 18 & Às Nove no Meu Blog & 5160 \\
\hline 19 & Pirata Mania & 4998 \\
\hline 20 & Geração Benfica & 4906 \\
\hline 21 & Blasfémias & 4775 \\
\hline 22 & Quadripolaridades & 4405 \\
\hline 23 & 5 dias & 4320 \\
\hline 24 & O Insurgente & 4080 \\
\hline 25 & Delito de Opinião & 4042 \\
\hline 26 & Gatas QB & 4002 \\
\hline 27 & Arrastão & 3961 \\
\hline 28 & Restos de Colecção & 3626 \\
\hline 29 & Cinco Quartos de Laranja & 3585 \\
\hline 30 & A Dona de Casa Perfeita & 3476 \\
\hline
\end{tabular}

Fonte: Blogómetro (blog Aventar)

Como se pode verificar nessa lista, o primeiro blog político que aí aparece, o Blasfémias, surge em 210 lugar e tem 4775 visitas diárias, o que representa apenas $9,7 \%$ do número de visitas diárias do blog que surge em 1일. lugar, o Visão de Mercado, dedicado ao futebol (marcam-se, em negrito, outros blogs políticos que constam também na lista dos trinta mais lidos: 5 dias, 0 Insurgente, Delito de Opinião e Arrastão).

É claro que, se considerarmos, por exemplo, o conjunto dos primeiros vinte blogs políticos que constam do Blogómetro (ver Tabela 2), a média diária de leitores passa a ser muito mais significativa: 42.016 , o que representa, seguramente, mais do que a média diária de alguns dos diários portugueses de referência - mas, ainda assim, longe das audiências de milhões dos canais televisivos. 
Tabela 2 - Vinte blogs políticos mais lidos (20 de julho de 2013)

\begin{tabular}{|c|c|c|c|}
\hline No & Pos. & Nome & Média Visitas \\
\hline 1 & 21 & Blasfémias & 4775 \\
\hline 2 & 23 & 5dias & 4320 \\
\hline 3 & 24 & O Insurgente & 4080 \\
\hline 4 & 25 & Delito de Opinião & 4042 \\
\hline 5 & 27 & Arrastão & 3961 \\
\hline 6 & 31 & Aventar & 3467 \\
\hline 7 & 34 & 31 da Armada & 2741 \\
\hline 8 & 35 & Jugular & 2323 \\
\hline 9 & 36 & Abrupto & 2218 \\
\hline 10 & 48 & Estado Sentido (no Sapo) & 1655 \\
\hline 11 & 49 & AspirinaB & 1617 \\
\hline 12 & 55 & Não votem, pensem. & 1462 \\
\hline 13 & 57 & Pantominocracia & 1406 \\
\hline 14 & 77 & Entre as brumas da memória & 1040 \\
\hline 15 & 92 & Forte Apache & 854 \\
\hline 16 & 100 & Cantigueiro & 684 \\
\hline 17 & 114 & Vai e Vem & 578 \\
\hline 18 & 170 & Farpas & 317 \\
\hline 19 & 179 & Em 2711 & 288 \\
\hline 20 & 217 & O Informador & 188 \\
\hline & & & 42.016 \\
\hline
\end{tabular}

Fonte: Blogómetro (blog Aventar)

No entanto, o número de blogs políticos existentes ou o seu número de leitores são apenas dois aspectos da influência desse tipo de blogs - e, provavelmente, nem sequer os mais importantes. De fato, e como observaram Drezner e

${ }^{4} \mathrm{~A}$ versão inicial do texto é de 2004.

${ }^{5}$ Tradução livre do original: "In this paper, we have sought to provide an answer to a perplexing question for political scientists - why do blogs sometimes have real political consequences, given the relatively low number of blog readers in the overall population?"

${ }^{6}$ Tradução livre do original: "If the mainstream mídia constructs focal points through which political actors must operate, the blogosphere has the capacity to construct focal points through which the mídia operates."
Farrell já há alguns anos", os blogs colocam uma "questão desconcertante" aos cientistas políticos: "porque é que os blogs, às vezes, têm consequências políticas reais, dado o número relativamente baixo de leitores de blogs no conjunto da população?" (2008b, p. 28) . $^{5}$ A resposta a esta questão reside, segundo os autores, na influência que os blogs têm na esfera mediática tradicional e, ergo, na esfera política - já que, como vimos, elas tendem a fundir-se como "parlamento mediático". Quanto à explicação desta influência da blogosfera na mediasfera, radicam-na Drezner e Farrell em quatro razões principais: incentivos materiais, rede de laços pessoais, expertise e velocidade. Estas razões, as quais explicam porque é que os jornalistas leem blogs, permitem também perceber como é que os blogs influenciam os jornalistas e, assim, a esfera política, por meio de processos de agendamento e, sobretudo, de enquadramento. Como resumem os autores, "Se as mídias mainstream constroem pontos focais através dos quais os atores políticos devem operar, a blogosfera tem a capacidade de construir pontos focais através dos quais as mídias operam." (DREZNER; FARRELL, 2008b, p. 25)6. Assim, a influência dos blogs na política e a sua importância são mais indiretas do que diretas - o que não significa que sejam menores.

No entanto, isso não quer dizer que os blogs não têm - ou não procuram ter uma influência direta e visível na política, principalmente em campanhas eleitorais. No caso português, a utilização dos blogs em campanhas políticas verificou-se logo nas presidenciais de 2006, para as quais foram criados blogs de apoio aos candidatos, como foi o caso do Pulo do Lobo (Cavaco Silva), Super Mário (Mário Soares) e Quadrado (Manuel Alegre). Já nas legislativas de 2009, foram criados blogs de apoio ao PS (o Simplex), ao PSD (o Jamais), e ao CDS (o Rua Direita) (PENA; LUÍS, 2009). Enquanto o Simplex (PS) congregava 40 autores, o Jamais congregava 32; desde a sua criação, respetivamente em 22 e 21 de julho, até à véspera das eleições (que tiveram lugar em 27 de setembro), os dois blogs publicaram um total de 2245 posts e tiveram mais de 320.000 visitas (MOURA, 2009, p. 34). 
${ }^{7}$ Ver De Sá (2010).

${ }^{8}$ Ver De Sá (2011).

${ }^{9}$ Ver Naves (2011).

${ }^{10}$ Para dois exemplos recentes, cf. O FIM, 2012.

${ }^{11}$ Tradução livre do original: "The latest, and perhaps gravest, challenge to the journalistic establishment is the blog."

${ }^{12}$ MORAIS, 2013: 217 et seq.
Ainda no contexto da campanha para as legislativas de 2009, Paulo Querido - um conhecido jornalista e pioneiro da blogosfera portuguesa - organizou a iniciativa BlogConf, uma conferência que, no dia 27 de julho de 2009, pôs frente a frente, durante cerca de três horas, o então primeiro-ministro e candidato José Sócrates e vinte bloggers de várias tendências políticas (GRILO, 2009).

Também Passos Coelho, o atual primeiro-ministro, quando na oposição, fez amplo uso destes encontros com bloggers nas suas várias modalidades: almoços com bloggers ( 13 de janeiro de 2010) ${ }^{7}$, jantares com bloggers (18 de março de 2011) $)^{8}$, conferências de imprensa para bloggers (15 de maio de 2011) $)^{9}$ etc. Estranhamente, ou talvez não, o comércio dos políticos com os bloggers parece ter tendência para terminar mal os primeiros passam da oposição para o governo.

Por outro lado, são vários e conhecidos os caso de bloggers que passaram a assessores do governo ${ }^{10}$, quando não mesmo a membros do mesmo - e, se bem que tal não tenha a ver exclusivamente com a qualidade de blogger, certamente que esta não deixará de dar o seu contributo, ao propiciar notoriedade e influência na blogosfera e na esfera mediática e política. Há, aliás, quem pretenda mesmo ver, nos blogs, um alfobre para recrutamento direto de políticos - como teria sido o caso do atual deputado socialista João Galamba, alegadamente selecionado por José Sócrates para ser o número 3 por Santarém nas eleições legislativas de 2009 devido à sua notoriedade como blogger (PENA; LUÍS, 2009).

\section{A relação entre os blogs e as mídias mainstream}

A questão da influência dos blogs que acabamos de tratar, liga-se de forma direta a uma outra questão: a da relação entre os blogs e as mídias mainstream. A questão é tanto mais relevante quanto um autor como Posner (2005) defende que "o blog é o desafio mais recente e talvez mais grave à instituição jornalística" ${ }^{11}$.

Para nos referirmos de novo ao estudo de Elsa Morais ${ }^{12}$, a maior parte dos 20 blogs aí analisados (60\%) recorre a hiperligações para as mídias nacionais mainstream sobretudo o Público, o I e o Diário de Noticias, verificando-se pouca presença da rádio e da TV e a ausência dos media regionais (o que é coerente com o perfil dos bloggers referido atrás), sendo também relevante o recurso aos vídeos do youtube.

No entanto, os blogs introduzem uma grande novidade em relação aos jornais que citam: os temas que tratam não apenas não coincidem com os dos jornais, mas também, e sobretudo, são tratados de forma diferente: enquanto os jornais se centram nos protagonistas - indivíduos e instituições -, os blogs centram-se nas ideias. Isto é explicável, em primeiro lugar, porque os jornais são mídias noticiosas, enquanto os blogs são media opinativos - dando origem, assim, uma espécie de "divisão do trabalho" informativo (Ibid., p. 225 et seq.), Nesse sentido, os blogs políticos não fazem propriamente jornalismo, mas aquilo a que, por analogia com outros domínios, poderíamos chamar "meta-jornalismo", jornalismo sobre o jornalismo - é desta forma que eles influem na agenda mediática e, assim, na própria agenda pública. Eles funcionam como uma espécie de provedoria generalizada dos mídia mainstream.

É certo que esta autonomia relativa dos blogs em relação aos mídia mainstream pode ser aduzida como um argumento contra a tese da "refeudalização" da blogosfera, de que trataremos adiante. Contudo, e contra as perspetivas mais otimistas sobre esta autonomia, convirá ter sempre presente a advertência de Hannah Arendt de que "a liberdade de opinião é uma farsa se a informação sobre os fatos não é garantida e se não são os próprios fatos que constituem o objeto de debate" $\left(1983\right.$, p. 238) ${ }^{13}$. Foi precisamente por terem consciência da importância e do peso dos fatos que regimes como os de Stalin procuraram apagar das fotografias os seus inimigos e rivais políticos, alguns deles já depois de apagados da própria vida; ou que regimes como o de Hitler alicerçaram o seu poder no lema de que uma

\footnotetext{
${ }^{13}$ Tradução livre do original: "Freedom of opinion is a farce unless factual information is guaranteed and the facts themselves are not in dispute."
} 
mentira mil vezes repetida passa a ser verdade. A esta relação criativa com os fatos, que é o chão de todos os regimes totalitários, chama-se há muito propaganda.

Para além disso, é preciso considerar que a afirmação de que enquanto os jornais nos revelam os fatos, os blogs propiciam-nos opiniões sobre eles não é totalmente exata - já que, por um lado, há uma parte importante do jornalismo que é opinativo (há mesmo quem defenda que, por mais factual que se pretenda, todo ele o é) e, por outro lado, há blogs que noticiam fatos em primeira mão.

É precisamente nesse âmbito que tem de se colocar a questão de agendamento (agenda-setting) por parte dos blogs. Se éverdade que a função de enquadramento (framing) dos blogs é mais ou menos evidente e permanente - ela decorre do próprio carácter intrinsecamente opinativo dos blogs -, a função de agendamento parece ser menos percetível e mais rara, ainda que também exista e se manifeste, por vezes, de forma particularmente agressiva. Isto deve-se, antes de mais nada, às limitações de tempo, dinheiro e recurso que os bloggers têm para a descoberta e investigação dos fatos, particularmente quando comparados aos mídia mainstream (DREZNER; FARRELL, 2008).

Procuramos, em outro trabalho (SERRA, 2009), analisar alguns casos, estrangeiros e nacionais, em que a função de agendamento por parte dos blogs se encontra patente. Daremos aqui um outro exemplo, mais recente: em 19 de julho de 2012, João Silva Jordão escreve, no seu blog Casa das Aranhas, um post intitulado $A$ Maçonaria em Portugal - uma história de corrupção e conspiração (JORDÃO, 2012). No dia 01 de agosto de 2012, alguém que assina António José coloca, nesse post, um comentário que consiste numa lista de centenas de nomes. No dia 30 de agosto de 2012, na revista Sábado, o jornalista e investigador de temas da Maçonaria António José Vilela publica um artigo intitulado Nomes da Maçonaria revelados, que informa, em lead, que “Os 'irmãos' do Grande Oriente Lusitano estão em pânico desde que foram colocados na Internet os nomes de 1.438 maçons" (VILELA, 2012, p. 49), referindo-se à lista do blog Casa das Aranhas, cuja veracidade terá se confirmado - apesar de ela conter pessoas que já morreram ou foram expulsas da organização maçônica, e omitir outras que entretanto teriam entrado na mesma. Sobre a forma como a lista terá sido obtida, um dos responsáveis da organização maçónica fala na possibilidade de ter havido uma "intrusão no sistema informático" daquela (VILELA, 2012, p. 49).

Ainda no dia 30 de agosto, a lista do blog Casa das Aranhas e a peça da Sábado são referidas nas várias mídias mainstream nacionais, como é o caso do Correio da Manhã (CORREIO DA MANHÃ, 2012), do Diário de Notícias (ANTUNES, 2012), do Expresso (PEREIRA, 2012), do Jornal de Negócios (JORNAL DE NEGÓCIOS, 2012), ou da TVI24 (TVI24, 2012).

Este exemplo mostra as principais características do agendamento feito pelos blogs: ele é, em geral, uma agendamento intermediático dos blogs sobre os mídia mainstream - em regra, primeiro os jornais ou as revistas, e só depois as televisões - e, a partir deles e por intermédio deles, sobre a agenda pública e política. Ele mostra, também, como os blogs, por não estarem sujeitos às regras e filtros profissionais e deontológicos dos mídia mainstream, podem publicar fatos e dados que aqueles não poderiam publicar, ou não poderiam publicar de maneira tão expedita.

Uma outra questão importante na discussão da relação entre os blogs e os mídia mainstream é aquela a que, seguindo autores como Goldman (2008) e Coady (2011), chamaremos a validade epistémica dos blogs, ou seja, a sua capacidade para atingirem a verdade, ou, como também se diz, a "verdade dos fatos".

Os dois autores referidos ilustram, precisamente, as duas posições antagônicas que podem ser - e têm sido - defendidas em relação a essa questão: enquanto 
${ }^{14}$ Tradução livre do original: "[...] the blogosphere as a whole has a better error-correction machinery than the conventional media do."

${ }^{15}$ Tradução livre do original: "It's as if The Associated Press or Reuters had millions of reporters, many of them experts, all working with no salary for free newspapers that carried no advertising."

\footnotetext{
${ }^{16} \mathrm{~A}$ esse respeito poderíamos mesmo colocar a hipótese de que o esquema que caracteriza a "esfera pública burguesa" se aplica, de fato, à evolução de cada nova mídia - no sentido de que, no início, oferece potencialidades de ampliação da esfera pública que, a breve trecho, serão alvo de uma "refeudalização" por parte das instituições dominantes, econômicas, políticas ou outras.
}

Goldman duvida da capacidade dos blogs de atingirem a verdade por não utilizarem os filtros (gatekeepers) utilizados pelos media convencionais (conventional mídia), já que Coady acha não só que os blogs utilizam filtros, ainda que diferentes, mas também que esses filtros até serão mais eficientes do que os dos media convencionais, podendo assim atingir a verdade factual.

Ao contrário do que acontece nos mídia convencionais, nos blogs os filtros são aplicados a posteriori, no sentido de que, se um blog publicar algo que seja falso ou incorreto, será prontamente objeto de reparo por parte de outros bloggers ou dos seus próprios leitores - e, assim, será mais ou menos rapidamente obrigado a retificar o que escreveu, sob pena de cair em descrédito junto dos seus pares e leitores. Isso leva Posner (2005) a considerar que "a blogosfera como um todo tem uma máquina de correção de erros melhor do que os meios de comunicação convencionais"14, ela seria comparável a uma Associated Press ou Reuters com "milhões de repórteres, muitos deles especialistas, todos trabalhando sem salário para jornais gratuitos e sem publicidade" (POSNER, 2005, s.p) ${ }^{15}$.

É preciso considerar, por outro lado, que a prática do gatekeeping tradicional, por parte dos media convencionais, não tem evitado que mesmo alguns dos mais conceituados publiquem também as suas falsidades e incorreções, algumas bem graves do ponto de vista da deontologia do jornalismo. Referimo-nos, por exemplo, a casos como o de Jayson Blair, o repórter do The New York Times que teve de se demitir do jornal em maio de 2003 após a descoberta de vários episódios de plágio e de fabricação das suas histórias. Ou do caso de Dan Rather, da CBS, que nas eleições presidenciais de 2004 deu uma falsa notícia sobre o candidato George Bush, tendo sido obrigado a deixar o CBS Evening News em 2005 e a estação televisiva em 2006. Ou ainda do caso do jornal News of the World, um jornal centenário que pertencia ultimamente a Rupert Murdoch e que foi obrigado a fechar em 07 de julho de 2011 após um escândalo relacionado com escutas de telemóveis por parte dos seus repórteres.

\section{Os velhos problemas da "esfera pública"}

Outra das questões que os blogs têm suscitado - à semelhança, aliás, do que tem acontecido com os vários "novos" mídia, quando emergem - é a de saber se representarão um alargamento e aprofundamento da esfera pública. Assim, a primeira tese de doutoramento que se debruça, em Portugal, sobre o tema da blogosfera política, elege como pergunta de investigação a seguinte:

Serão, assim, os blogs promotores de pluralismo e de diversidade como princípios estruturantes da democracia, contribuindo para a esfera pública com perspectivas divergentes, novas, diferentes, alternativas? (MORAIS, 2013, p. 12)

Esta é, de fato, uma questão crucial, em relação à qual a maioria dos bloggers políticos estaria, certamente, disposta a responder afirmativamente. Assim, e para darmos apenas um exemplo, um dos fundadores da blogosfera política portuguesa, Pedro Mexia, vê naquela não só “um espaço de opinião 'mais diferenciado' do que o dos jornais [mas também] [...] uma repolitização do espaço público, no sentido ideológico e não no sentido partidário" (MEXIA s.d. apud PENA; LUÍS, 2009).

Todavia, a blogosfera portuguesa evidencia, desde os seus inícios, as assimetrias assinaladas à chamada "esfera púbica burguesa", e reconhecidas pelo próprio Habermas (1992); e, segundo certos autores, sobretudo a partir de 2009, ela tem evidenciado também uma verdadeira "refeudalização" nos termos em que é caraterizada por Habermas (1992) ${ }^{16}$. Tratemos de cada um destes aspetos de per si.

No que se refere às assimetrias, elas revelam-se claramente quando analisamos, ainda que de forma elementar, o perfil sociodemográfico dos bloggers. 
Os vários dados estatísticos e inquéritos têm confirmado que os bloggers são predominantemente jovens, masculinos, de zonas urbanas, com estudos superiores e profissões intelectuais - mesmo se as percentagens concretas variam de estudo para estudo.

Assim, e para referirmos apenas alguns desses estudos, os dados do questionário "A Sociedade em Rede em Portugal 2006" permitiam concluir que, até então, 40\% dos bloggers tinham menos de 18 anos, representavam 63\% do sexo masculino e incluíam 55\% de estudantes do ensino secundário (CARDOSO; ESPANHA; CHETA, 2008, p. 12). Por seu lado, os dados de inquérito levado a cabo por Carvalho e Casanova (2010, p. 101-2) mostram que "os produtores de blogs de opinião e intervenção pública" representam $80,7 \%$ de homens, dos quais cerca de $56 \%$ se situam entre os 26 e os 45 anos, localizados em dois eixos principais, LisboaSetúbal (mais de $50 \%$ da amostra) e Porto-Braga (17,5\%), dos quais mais de $90 \%$ têm escolaridade de grau superior e são sobretudo "profissionais técnicos de enquadramento e liberais, dirigentes e empresários" (CARVALHO; CASANOVA, 2010, p. 101-2). Por fim, os dados do questionário levado a cabo por Elsa Morais aos bloggers dos 20 blogs políticos mais lidos do Blogómetro, obtendo um total de 59 respostas, conclui que são majoritariamente masculinos $(86,5 \%)$, urbanos ( $56 \%$ vive na área da Grande Lisboa e $24 \%$ na área do Grande Porto), têm idades entre os 30 e 50 anos (72,8\%), e exercem profissões maioritariamente intelectuais, muito qualificadas, de que se destacam a docência universitária e o jornalismo (MORAIS, 2013, p. 184-9).

No que se refere à questão da eventual "refeudalização" da blogosfera, Drezner e Farrell (2004) colocavam a hipótese de que, à medida em que os blogs se tornassem "politicamente mais influentes", poderíamos esperar que se tornassem "mais diretamente integrados na 'política como de costume', perdendo um pouco de seu

${ }^{17}$ Tradução livre do original: "To the extent that blogs become more politically influential, we may expect them to become more directly integrated into "politics as usual," losing some of their flavor of novelty and immediacy in the process." sabor de novidade e rapidez no processo." (DREZNER; FARRELL, 2008b, p. 28) ${ }^{17}$. Como vimos, no caso português esse processo de integração verificou-se a partir das eleições presidenciais de 2006, podendo-se considerar como mais ou menos estabelecido já nas eleições legislativas de 2009. Ora, essa integração é vista por vários blogueiros, jornalistas e intelectuais como uma verdadeira submissão dos blogs aos interesses midiáticos e políticos dominantes.

Assim, referindo-se à conferência de José Sócrates com os bloggers de 27 de julho de 2009, o blogger, articulista, historiador e político José Pacheco Pereira, num texto intitulado Sócrates entre os bloggers..., menciona a perda de autonomia da blogosfera política em relação aos jornais e à vida partidária, e a consequente perda da "voz crítica da blogosfera".

Hoje a blogosfera está rendida ao mainstream, com os mesmos defeitos do mainstream. Tem o mesmo tom, a mesma agenda, os mesmos temas, que a imprensa, e mesma preocupação de carreira e ascensão que tem um jovem de uma jota. Claro que há exceções, mas esta é a regra. (PEREIRA, 2009, s.p.)

Num texto escrito na mesma época, intitulado $A$ Era dos Extremos lo fim de certa blogosfera), Bruno Sena Martins pronuncia-se mais ou menos no mesmo sentido, assinalando:

[o fim de] [...] uma era em que o debate político ia sendo fortemente alimentado pelas franjas do espectro político e em que a discussão vivia de questões marcadamente ideológicas [e a sua substituição por uma blogosfera que é] [...] um reflexo fiel da esfera pública portuguesa [em que] [...] o debate ideológico foi largamente substituído pelas questões pragmáticas do governo da república e a crítica tendencialmente indiscriminada foi dando lugar aos rigores da lealdade partidária. (MARTINS, 2009, s.p.) 
Os blogs Jamais e Simplex seriam, precisamente, os "sintomas cintilantes" dessa nova era.

Que essa alteração na blogosfera não era conjuntural mostra-o, também, o fato de que diagnósticos semelhantes aos anteriores foram sendo feitos posteriormente, de forma regular.

Desse modo, em artigo de setembro de 2011, António Guerreiro escrevia sobre "Os blogs e a estrutura mafiosa do poder", entendendo aqui "organização mafiosa" não como uma organização criminosa, mas como:

uma organização que sobrevive através da construção de uma teia de relações "familiares" e que faz da propaganda a arma principal do seu desígnio: a autoproteção que garante a sobrevivência. (GUERREIRO, 2011, s.p.)

Por outro lado, em um post de 26 de março de 2012, o blogueiro victorangelo, do blog Vistas Largas, escrevia que:

A maioria dos blogs "políticos" portugueses acrescenta zero ao que vem na imprensa [...]. Não trazem nada de novo, não acrescentam grande coisa à reflexão nem ao conhecimento. Ou seja, acabam por quase não ter impacto na cena política nacional e na elaboração de uma opinião pública alternativa. Sem contar que uma grande maioria desses blogs mostra um alinhamento cego com um ou outro partido, sem independência de espírito. (VICTORANGELO, 2012, s.p.)

Dados estes diagnósticos, não admira que o referido José Pacheco Pereira (se) pergunte, num post do blog Abrupto de 6 de dezembro de 2012, "por que razão os blogs têm cada vez menos importância?", atribuindo a "profunda crise" da blogosfera política a três razões, entre outras:

a agenda dos blogs tornou-se a agenda comunicacional; os blogs tornaramse espelhos miméticos dos partidos e fracções políticas, e os blogs são hoje uma "área de negócio", quer em termos da gestão de carreiras individuais, principalmente no plano político, quer para agências de comunicação, marketing etc., que actuam nesse meio para servirem os seus clientes. (PEREIRA, 2012, s.p.)

O que dizer dessas posições sobre a perda de autonomia da blogosfera? Diremos que, tal como acontece com a questão da "refeudalização" da "esfera pública burguesa", convém perguntar se não há também aqui, em relação à blogosfera, uma crítica demasiado em bloco. Ou seja: tal como nos mass mídia "refeudalizados" sempre houve e continua a haver espaços de crítica e de debate dotados de virtualidades democráticas, o mesmo acontece na blogosfera. Apesar dos blogs que hoje se encontram "refeudalizados", há muitos outros blogs - talvez a maioria - que continuam a obedecer à sua vocação original de consciencialização e crítica do que se passa no sistema político-midiático.

\section{Considerações Finais}

Voltemos ao dito de Liebling, citado na introdução: parece inegável que "a liberdade de imprensa é garantida apenas àqueles que possuem uma". No entanto, a Web 2.0, em geral, e a blogosfera, em particular, obrigam-nos também a colocar a questão inversa: e o que acontece à liberdade de imprensa quando todos podem ter uma?

Do lado da receção, o resultado não pode deixar de ser a fragmentação do espaço público (RODRIGUES, 2006), e a impossibilidade de se fixarem os temas 
que constituem a "opinião pública" (HABERMAS, 2006). Do lado da produção, o que temos é aquilo a que Papacharissi (2009) chama "narcisismo cívico", isto é, um conjunto de indivíduos que desafiam constantemente os limites do público e do privado, fazendo com que cada uma das esferas interpenetre cada vez mais a outra - e tudo isto numa lógica de "agonismo pluralista" inconciliável com o alegado consenso que deveria caraterizar a "esfera pública".

Todavia, o fato de os blogs políticos não poderem ser vistos como uma nova "esfera pública" não implica que eles não sejam importantes de um ponto de vista cívico e político. Eles permitem aos cidadãos fazer chegar a sua voz à mídia e por meio dela aos agentes políticos; permitem-Ihes uma forma de "fazer política" que não se resume nem ao voto periódico e cerimonial, nem à mera manifestação ruidosa na praça pública - mas que pode muito facilmente articular-se com ambas as formas. Nesse sentido, eles representam, sem dúvida, um aumento de poder dos cidadãos que os produzem e utilizam.

É certo que, no decurso da sua ainda breve história, os blogs passaram de uma fase de afirmação a uma fase de institucionalização. No entanto, essa passagem não equivale, necessariamente, a uma submissão da blogosfera como um todo, aos ditames do sistema político-midiático, aé porque os blogs que protagonizam essa submissão acabam, mais tarde ou mais cedo, por ser vítimas dela: perdem credibilidade, leitores e influência. Ao perderem o seu sentido crítico, perdem aquilo que constitui a essência de um blog político; transformam-se numa voz entre as muitas outras que integram o sistema político-midiático.

Assim, os verdadeiros blogs políticos estão-e devem continuar a estar-à margem do sistema político-midiático, procurando criar nele uma irritação produtora de mudanças. Por conseguinte, não poderíamos estar mais em desacordo com as posições daqueles que, como Sullivan (2004), criticam os bloggers por ficarem às margens, por serem insurgentes que não querem governar. É precisamente às margens, pondo em prática aquilo a que o mesmo Sullivan chama a "ética da revolta", que os bloggers são realmente importantes e úteis do ponto de vista cívico e político.

\section{Referências Bibliográficas}

ANTUNES, R. P. Maçonaria: políticos, gestores e juízes entre os 1438 maçons expostos. DN Política. Disponível em: <http://www.dn.pt/politica/interior. aspx?content_id=2743058>. Acesso em: 27 jul. 2013.

ARENDT, $\mathrm{H}$. Truth and politics. In: Between past and future. Harmondsworth: Penguin Books, 1983, p. 227-264.

BLOGÓMETRO. Lista por média diária de visitas. Aventar. 20 jul. 2013. Disponível em: <http://blogometro.aventar.eu/mt/2013-07-20/?page=60>. Acesso em: 27 jul. 2013.

CANAVILHAS, J. Blogs políticos em Portugal: o dispositivo criou novos actores? In: CORREIA, J. C. (Org.). Comunicação e política. Covilhã: Livros Labcom, 2005, p. 85-111.

CARDOSO, G; ESPANHA, R.; CHETA, R. (Coord.). Blogs e blogosfera.pt. Lisboa: Obercom, 2008.

CARVALHO, T.; CASANOVA, J. L. Esfera pública, democracia e internet: os bloggers em Portugal. Observatorio (OBS*) Journal, v. 4, n. 2, 2010, p. 91-118. 
COADY, D. An epistemic defence of the blogosphere. Journal of Applied Philosophy, v. 28, n. 3, 2011, p. 277-294.

CORREIO DA MANHÃ. Nomes de 1438 maçons revelados na Internet. Disponível em: <http://www.cmjornal.xl.pt/detalhe/noticias/nacional/politica/nomes-de1438-macons-revelados-na-internet>. Acesso em: 27 jul. 2013.

DE SÁ, F. M. Pedro Passos Coelho almoça com Bloggers - Parte 1. Aventar. Disponível em: <http://aventar.eu/2010/01/13/pedro-passos-coelho-almocacom-bloggers-parte-1/>. Acesso em: 27 jul. 2013.

- Pedro Passos Coelho jantou com bloggers. Albergue Espanhol. Disponível em: <http://albergueespanhol.blogs.sapo.pt/923640.html>. Acesso em: 27 jul. 2013.

DREZNER, D. W.; FARRELL, H. Introduction: blogs, politics and power: a special issue of Public Choice. Public Choice, v.134, n.1-2, 2008a, p. 1-13.

. The power and politics of blogs. Disponível em: <http://www.yale.edu/ lawweb/jbalkin/telecom/dreznerandfarrellblogpaperfinal.pdf>. Acesso em: 19 jun. 2013. $15-30$.

The power and politics of blogs. Public Choice, v. 134, n.1-2, 2008b, p.

GILLMOR, D. We the media: grassroots journalism by the people, for the people. Sebastopol: O’Reilly Media, 2004.

GOLDMAN, A. I. The social epistemology of blogging. In: HOVEN, J.; WECKERT, J. (Eds.). Information technology and moral philosophy. Cambridge: Cambridge University Press, p. 111-22, 2008.

GRILO, R. BlogConf 1.0: José Sócrates. Ideias em série. Disponível em: <http:// www.ideiasemserie.net/files/blogconf.php>. Acesso em: 14 jul. 2013.

GUERREIRO, A. Os blogs e a estrutura mafiosa do poder. Expresso-Atual. Disponível em: <http://expresso.sapo.pt/os-blogs-e-a-estrutura-mafiosa-dopoder=f671314>. Acesso em: 19 jul. 2013.

HABERMAS, J. The structural transformation of the public sphere: an inquiry into a category of bourgeois society. Cambridge: Polity Press, 1989.

Further reflections on the public sphere. In: CALHOUN, C. (Ed.). Habermas and the public sphere. Cambridge: MIT Press, 1992, p. 421-461.

Political communication in media society: does democracy still enjoy an epistemic dimension? The impact of normative theory on empirical research. Communication Theory, v. 16, n. 4, p. 411-426, 2006.

JORDÃO, J. S. A maçonaria em Portugal - uma história de corrupção e conspiração. Casa das Aranhas. Disponível em: <http://casadasaranhas.wordpress. com/2012/07/19/a-maconaria-em-portugal-uma-historia-de-corrupcao-econspiracao/>. Acesso em: 28 jul. 2013.

JORNAL DE NEGÓCIOS ONLINE. Sociedades secretas: divulgação de 1.500 maçons na internet lança pânico. Negócios. Disponível em: <http://www.jornaldenegocios. pt/economia/detalhe/divulgaccedilatildeo_de_1500_maccedilons_na_internet_ lanccedila_pacircnico.html>. Acesso em: 27 jul. 2013. 
LUHMANN, Niklas. Complexidade societal e opinião pública. In: A improbabilidade da comunicação. Lisboa: Vega, 1993.

MARTINS, B. S. A era dos extremos (o fim de certa blogosfera). 5dias. Disponível em: <http://5dias.net/2009/08/07/a-era-dos-extremos-o-fim-de-certa-blogosfera/>. Acesso em: 22 jul. 2013.

MORAIS, M. E. Pluralismo e diversidade nos media em Portugal: a blogosfera política em rede. 386f. Tese (Doutorado em Ciências da Comunicação-Especialidade de Economia Política da Comunicação) - Universidade do Minho, Braga, 2013.

MOURA, L. M. Assimetrias de comportamentos na blogosfera política portuguesa. 60f. Dissertação (Mestrado em Sociologia - Especialidade em Comunicação e Cultura) - Instituto Universitário de Lisboa, Lisboa, 2009.

NAVES, L. Passos Coelho responde a perguntas de bloggers. Albergue Espanhol. Disponível em: <http://albergueespanhol.blogs.sapo.pt/1081346.html>. Acesso em: 27 jul. 2013.

O FIM. Combate de blogs. Disponível em: <http://combateblogs.blogspot.pt>. Acesso em: 26 jun. 2013.

PAPACHARISSI, Z. The virtual sphere 2.0: the internet, the public sphere, and beyond. In: CHADWICK, A.; HOWARD, P. N. (Orgs.). Routledge handbook of internet politics. Nova York: Routledge, p. 203-245, 2009.

PENA, P.; LUÍS, S. B. O blog é uma arma. Visão. Disponível em: <http://visao. sapo.pt/o-blog-e-uma-arma=f524691>. Acesso em: 20 jul. 2013.

PEREIRA, J. P. Perguntas que não levam a parte nenhuma: por que razão os blogs têm cada vez menos importância? Abrupto. Disponível em: <http://abrupto. blogspot.pt/2012/02/perguntas-que-nao-levam-parte-nenhuma.html>. Acesso em: 27 jun. 2013.

Sócrates entre os bloggers... Opinião, Sábado. Disponível em: <http:// www.sabado.pt/Opiniao/Jose-Pacheco-Pereira/Socrates-entre-os-bloggers. aspx>. Acesso em: 19 jul. 2013.

PEREIRA, M. Lista de maçons está online há quatro semanas: Mais de 1400 nomes do Grande Oriente Lusitano foram publicados num blog. Expresso. Disponível em: <http://expresso.sapo.pt/lista-de-macons-esta-ionlinei-haquatro-semanas=f749932>. Acesso em: 27 jul. 2013.

POSNER, R. A. Bad news. The New York Times. Disponível em: <http://www. nytimes.com/2005/07/31/books/review/31POSNER.html?_r=1\&pagewan\&>. Acesso em: 19 jul. 2013

RODRIGUES, C. Blogs e a fragmentação do espaço público. Covilhã: Livros Labcom, 2006.

SERRA, J. P. Os blogs e a questão do agendamento. Biblioteca On-Line de Ciências da Comunicação. Disponível em: <http://www.bocc.ubi.pt/pag/boccserra2-blogs. pdf>. Acesso em: 18 jul. 2013.

Novos media e participação política. Observatorio (OBS*) Journal, v. 6, n. 2 , p. $127-155,2012$.

SILVA, P. C. A emergência do cidadão jornalista: o caso do programa "Combate de Blogs" da TVI24. 127f. Dissertação (Mestrado em Ciências da Comunicação) Universidade do Porto, Porto, 2012. 
SIMMEL, G. Fashion. International Quarterly, v. 10, n. 1, p. 130-155, 1904.

SULLIVAN, A. Year of the insurgents. Time Magazine. Disponível em: <http:// www.time.com/time/magazine/article/0,9171,1009900,00.html>. Acesso em: 19 jul. 2013.

TVI24. Publicada lista de maçons na Internet: São mais de 1400 nomes ligados ao Grande Oriente Lusitano. Tvi24. Disponível em: <http://www.tvi24.iol. pt/aa---videos---sociedade/maconaria-macons-gol-grande-oriente-lusitanotvi24/1371447-5795.html>. Acesso em: 27 jul. 2013.

VICTORANGELO. Histórias de maldizer, sem mais. Vistas largas: Portugal é grande quando abre horizontes. Disponível em: <http://victorangelo.blogs.sapo. pt/393575.html>. Acesso em: 20 jul. 2013.

VILELA, A. J. (2012). Nomes da Maçonaria revelados. Revista Sábado, 30 ago., p. 49. 